\title{
Subsetores de Arte e Cultura nos jornais Folha de São Paulo e Público (2018) ${ }^{1}$
}

Arts and culture subsectors in Folha de São Paulo and Público (2018) Mariana Scalabrin Müller - CECS-UMinho

marianasmuller@gmail.com

https://doi.org/10.26619/978-989-9002-14-2.8

\begin{tabular}{|c||c|c|}
\hline Recebido / Received & Aceite / Accepted & Publicado / Published \\
30.05 .2020 & 18.06 .2020 & 15.01 .2021 \\
\hline
\end{tabular}

Como citar este capítulo / How to quote this chapter:

Müller, M. S. (2021). "Subsetores de Arte e Cultura nos jornais Folha de São Paulo e Público (2018)". In Lourenço, J. \& Lopes, P. (eds.), Comunicação, Cultura e Jornalismo Cultural. Lisboa: NIP-C@M \& UAL. (pp. 163-187), disponível em: https://repositorio.ual.pt/handle/11144/4756 DOI https://doi. org/10.26619/978-989-9002-14-2.8

1 Investigação desenvolvida no âmbito do Doutoramento FCT em Estudos de Comunicação: Tecnologia, Cultura e Sociedade, do qual a autora é bolseira (PD/BD/128179/2016).

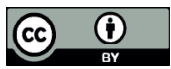




\section{Resumo}

Este capítulo apresenta resultados de uma Análise de Conteúdo (Neuendorf, 2002) aplicada a 632 peças publicadas em 2018, na seção digital de cultura dos jornais Folha de São Paulo e Público. Centra-se na análise do que designamos Subsetores de Arte e Cultura. Foram utilizadas palavras-chave sobre Brasil para selecionar a amostra do jornal Público e sobre Portugal para compor a amostra da Folha. Parte-se da perspetiva construcionista de compreensão do jornalismo (Alsina, 2009) e do entendimento de que a análise de coberturas permite a identificação de mapas de significado ou supostos consensos sobre a sociedade, em determinados períodos ou locais (Hall, Chritcher, Jefferson, Clarke \& Roberts, 1999). Nos dois jornais, os subsetores predominantes foram Música, Livros e Cinema. Entre os subsetores pouco representados estão Arte de Rua, Gastronomia, Design, Economia da Cultura, Performance e Política Cultural. 


\section{Abstract}

This chapter presents results of a Content Analysis (Neuendorf, 2002) applied to 632 pieces published in the digital culture section of the newspapers Folha de São Paulo and Público in 2018. It focuses on the analysis of what we call Arts and Culture Subsectors. Keywords about Brazil were used to select the sample from Público newspaper and about Portugal to compose Folha's sample. It is based on the constructionist perspective of journalism (Alsina, 2009) and on the understanding that the analysis of coverage allows the identification of maps of meaning or supposed consensus about society in certain periods or places (Hall, Chritcher, Jefferson, Clarke \& Roberts, 1999). In both newspapers, the predominant subsectors were Music, Books and Cinema. Street Art, Gastronomy, Design, Culture Economics, Performance and Cultural Policy are among the underrepresented sectors. 


\section{Introdução}

Este capítulo integra uma investigação maior sobre a cobertura jornalística da cultura no Brasil e em Portugal. Tem como particularidade o uso de uma perspetiva cruzada, ou seja, mapeia, a partir de palavras-chave, referências ao Brasil no jornal português Público e a Portugal no brasileiro Folha de São Paulo. Centramos nosso olhar a uma variável que designamos como Subsetores de Arte e Cultura.

Este texto inicia com uma perspectiva teórica sobre a prática jornalística e, a seguir, sobre o jornalismo cultural. Apresentamos, também, resultados de outras investigações que abordam subáreas da cultura. Na sequência, há uma descrição de nosso percurso teórico e a apresentação do panorama dos subsetores nos jornais Folha de São Paulo e Público em 2018, suas divergências e convergências.

\section{O processo de construção das notícias: aspectos rele- vantes}

O jornalismo cultural, foco deste capítulo, carrega inúmeras especificidades e, ainda assim, está ancorado em elementos estruturantes da prática. Conforme Baptista (2017) está também embrenhado nos mesmos constrangimentos que afetam qualquer outro exercício do jornalismo. Desse modo, iniciamos nosso percurso com a apresentação de alguns construtos teóricos sobre a prática jornalística que consideramos essenciais para a compreensão da cobertura de cultura. 
A partir da concepção de construção social da realidade (Berger \& Luckman, 2010), Alsina (2009) afirma que é atribuído aos jornalistas um papel socialmente legitimado e institucionalizado para construir a realidade social como uma realidade pública e relevante no contexto social. Desse modo, a construção social da realidade por parte dos média envolve a produção, a circulação e o reconhecimento do que é produzido. A relação entre jornalistas e seus destinatários é, portanto, essencial e se dá a partir de um contrato de confiança, que é social e construído historicamente (Alsina, 2009).

Assim, é necessário encarar o processo de construção das notícias como algo complexo. Na etapa de seleção dos fatos que serão transformados em peças, Hall et. al (1999) identificam a presença de uma ideologia profissional sobre o os fatos que devem ser transformados em notícias. Nessa etapa, os valores-notícia do jornalista são parte estruturante do processo, uma vez que fornecem critérios para se decidir, de forma rotineira, o que merece destaque ou não. Em uma segunda etapa, os fatos são inseridos em um contexto social familiar ao público, ou seja, são identificados e contextualizados pelos jornalistas a partir de um processo de significação que é social, já que leva em conta supostos conhecimentos culturais partilhados entre os membros de uma sociedade, que têm acesso aos mesmos mapas de significado.

O processo social de tornar um fato ou acontecimento inteligível é constituído por uma série de práticas jornalísticas que 
compreendem, conforme Hall et. al (1999, p.226), "suposições cruciais sobre o que é a sociedade e como ela funciona". Desse modo, a análise desses mapas de significado permitiria a identificação de interesses, valores e preocupações dominantes ou fundamentais em um determinado contexto. Destaca-se, assim, a importância da investigação sobre coberturas jornalísticas.

Para compreender o processo de construção das notícias, Berger (2003) aproxima o conceito de campo ${ }^{1}$, desenvolvido por Pierre Bourdieu, dos estudos de jornalimo. Assim, a autora (Berger, 2003) afirma que o campo do jornalismo detém, de forma privilegiada, o capital simbólico², o que significa que seu principal capital é a credibilidade. Quando seleciona fatos para serem transformados em notícia, o jornalismo os confere sentido e lugar no mundo por meio do seu discurso. Na edição, há uma disputa em torno do ato de nomear, que enfatiza o poder simbólico ${ }^{3}$. Isso se dá porque é esse ato que permite incluir ou excluir, legitimar ou não, dar voz, publicizar ou tornar público fatos, acontecimentos, sujeitos, movimentos etc. Ainda que o processo de elaboração

1 De acordo com Bourdieu (2004, 2005, 2008, 2010, 2011), o campo é um espaço simbólico com posições estruturadas em que agentes lutam por um capital comum. Assim, a sociedade estaria dividida em diferentes campos sociais, onde poder e espaço são disputados. Na perspectiva de Bourdieu, ainda haveria um princípio estruturador das ações sociais e comportamentos, que é necessário para conhecer as regras do jogo e, portanto, adquirido por meio da experiência e da posição no mundo social, o habitus. 2 Na conceituação de Bourdieu (2004, 2005, 2008, 2010, 2011), a noção de capital simbólico está inserida em uma proposta ampla, que busca compreender o mundo social. Trata-se de um sistema amplo de trocas dentro e através dos campos com ativos de diferentes tipos ou valores. Cada campo teria o seu capital simbólico ou recurso principal, capaz de gerar disputa.

3 Bordieu (2010) define o poder simbólico como um poder invisível que só pode ser exercido a partir da cumplicidade daqueles que não querem saber que lhe são sujeitos ou que o exercem. Trata-se, portanto, de um poder que necessita de reconhecimento. 
das notícias seja extenso e inclua diferentes profissionais, o poder simbólico está, para Berger (2003), concentrado na edição.

\section{Jornalismo cultural: visibilidade e mediação}

Para iniciar uma reflexão acerca do jornalismo cultural cabe especificar a respeito do que estamos falando. De forma resumida, abordamos aqui as seções designadas como culturais dentro dos média. Ou seja, de um espaço reservado para as temáticas que determinado meio de comunicação considera como cultural, assim como faz com outros temas como Economia, Política ou Saúde. Interessa-nos, portanto, o que os média classificam como cultural e, consequentemente, de que modo o fazem. Tendo em conta os construtos teóricos que elencamos anteriormente, ao classificar determinado produto ou sujeito, por exemplo, como pertencente à seção cultural, a prática jornalística contribui para a sua legitimação e, ao mesmo tempo, para a construção de uma noção partilhada sobre o que é cultural e o que não é.

Tanto os suplementos quanto a cobertura diária de cultura, em seções digitais ou impressas, carregam a questão da visibilidade como marca. Ser abordado pelo jornalismo cultural significa ser destacado no todo da produção cultural e, por consequência, acumular prestígio. Trata-se de uma lógica inserida no processo de criação, circulação e consagração de bens simbólicos, de Bourdieu (2004, 2005, 2008, 2011), e também na proposta de mediadores culturais (Janssen \& Verboord, 2015). 
De forma sucinta, podemos dizer que Bourdieu (2005) apresenta um sistema de relações objetivas entre as diferentes instâncias definidas pela função que cumprem entre produção, reprodução e difusão de bens simbólicos. Assim, a produção cultural é resultado de um jogo amplo, que resulta em uma disputa pela hegemonia da consagração. Essa disputa acaba por favorecer a lógica da distinção, seja de um livro, de um artista ou de uma instituição. Quando seleciona o que será notícia, o jornalismo acaba por estar inserido nessa lógica de distinção e de consagração de determinados produtos culturais em detrimento de outros.

Nessa perspectiva, o prestígio é considerado um capital de viés simbólico, reconhecido e útil no campo da arte, capaz de conferir autoridade (Bourdieu, 2004, 2008). Quem detém prestígio, um artista, por exemplo, também tem a capacidade de consagrar outros artistas, produtos ou manifestações artísticas. Desse modo, a noção de assinatura ou de grife é visível nas coberturas jornalísticas da cultura. Em uma lógica circular, podemos dizer que a cobertura cultural é uma instância de legitimação para artistas, produtos ou instituições culturais e, ao mesmo tempo, o prestígio desses agentes contribui, de forma positiva, para a consagração do meio de comunicação social em questão.

Tendo em conta, também, as concepções desenvolvidas por Pierre Bourdieu a respeito dos bens simbólicos, Janssen e Verboord (2015) enfatizam o papel dos chamados mediadores culturais ou gatekeepers. Trata-se de papeis fundamentais no processo de consagração, atuando na manutenção da reputa- 
ção e, até mesmo, na sobrevivência dos artistas. Uma série de profissionais atuam como mediadores, entre eles os jornalistas, com atuação em dois momentos: na venda dos produtos e em uma fase de avaliação, classificação e criação de significado sobre eles. A primeira delas envolve estratégias de relações públicas e de assessoria de imprensa com o objetivo de conseguir espaço na cobertura jornalística. Na segunda etapa, destaca-se o papel de críticos e resenhistas, que acabam por interferir na reputação daquilo que avaliam e, ao mesmo tempo, reforçam a sua autoridade.

Compreendemos, então, que a visibilidade e o prestígio são fundamentais para agentes e produtos culturais e que o jornalismo tem um papel importante nesse ciclo, uma vez que é capaz de atuar como mediador entre produtores (artistas, instituições, coletivos etc) e consumidores culturais (espectadores, leitores, ouvintes etc). Reforça-se, então, a importância de mapear a presença de determinados setores e subsetores de arte e cultura na cobertura jornalística em diferentes períodos e locais.

Há uma série de estudos longitudinais e comparativos que buscam fazer essa análise em diferentes contextos. Em uma investigação focada em jornais populares e de elite dos Países Baixos, Janssen (1999) mapeou quais bens culturais haviam ganhado ou perdido espaço na cobertura entre 1965 e 1990. Os temas que ganharam diferem um tanto entre os dois tipos de jornais selecionados: música pop, literatura e cinema nos jornais de elite; música pop, musicais, concertos e espetáculos do tipo cabaret 
nos populares. Por outro lado, as subáreas que mais perderam espaço são as mesmas nas duas categorias de jornais: teatro, música clássica e arte aplicada (inclui arquitetura, moda e design).

Também foi possível identificar uma alteração nos tópicos predominantes em uma investigação que analisou quatro jornais com diferentes perspectivas editoriais na Dinamarca, entre 1890 e 2008. Teatro e cultura folk, predominantes no começo do século XX, perderam espaço para, entre outros temas, música popular, os média e a chamada cultura de celebridades (Kristensen, 2010). Ao mesmo tempo, Kristensen (2010) identifica uma tendência híbrida, ou seja, de haver mais de um subsetor em uma mesma peça. A autora acredita que o jornalismo cultural está expandindo seu foco, sua interpretação e sua apresentação da cultura, em linha com mudanças na indústria do consumo e com a competitividade e o profissionalismo no campo dos média.

Em uma investigação recente realizada em quatro diários, um semanário e uma revista portugueses, focada em peças que ganharam destaque na primeira página, foi identificado um predomínio dos mesmos temas nos dois anos analisados: Música, Literatura e Cinema. Houve em crescimento leve entre 2000 e 2010: Música passou de $22 \%$ para 23\%, Literatura de $19 \%$ para 22,9\% e Cinema de 18\% para 21,9\% (Baptista, 2017). Os resultados são semelhantes aos encontrados por Santos Silva (2016) em uma análise que considerou apenas a edição digital do jornal 
Público em 2014: Cinema (31\%), Música (22\%) e Livros (11\%) predominaram.

\section{Descrição metodológica}

Este capítulo apresenta, como já mencionamos, uma parte dos resultados encontrados em uma investigação maior e, desse modo, seu desenho de investigação está estruturado tendo em conta os objetivos da investigação como um todo. Apresentamos aqui, de forma breve, elementos essenciais para a compreensão dos resultados, por exemplo, a definição do objeto empírico, a construção da amostra e o uso da Análise de Conteúdo.

\subsection{Objeto empírico: os jornais Folha de São Paulo e Público}

A escolha dos jornais Folha de São Paulo e Público estruturou-se em torno de dois elementos principais, os objetivos do projeto de investigação e a viabilidade da coleta de dados. A composição do objeto empírico com um jornal brasileiro e um português se deve à investigação maior em que esse capítulo se insere, o foco na edição digital e a atenção ao modo como estruturam a cobertura jornalística da cultura também. Dentro da lógica dos objetivos de investigação, também privilegiamos jornais apresentados como nacionais em detrimento dos regionais. Em relação à viabilidade, destacamos a busca por dois média que apresentassem um arquivo digital com diferentes possibilidades de busca (nomeadamente uso de filtros, seleção temporal e palavras-chave). De forma muito breve, podemos dizer que esse 
foi o caminho que nos levou até o jornal brasileiro Folha de São Paulo e ao português Público.

Em sua trajetória enquanto jornais impressos, tanto Público quanto Folha, concedem um espaço relevante para a cobertura de cultura. Em um momento em que cresce o encerramento dos suplementos culturais impressos em diferentes países, os dois jornais mantêm seus cadernos impressos circulando e, ainda, trazem a marca desses suplementos para o ambiente digital. 0 Ípsilon ${ }^{4}$, suplemento cultural semanal do jornal Público, é também o nome da seção digital de cultura do Público e, em paralelo, a llustrada, suplemento diário cultural da Folha, dá nome a seção digital de cultura do jornal ${ }^{5}$.

Há, no entanto, algumas diferenças na forma como organizam sua cobertura no ambiente impresso. A Folha mantém um caderno diário chamado Ilustrada e um suplemento semanal, o Ilustríssima, focado em debates do que designa como grandes temas da cultura. Há, ainda, o caderno semanal chamado Turismo. Já no Público, o Ípsilon é o suplemento cultural semanal e a cobertura diária está no corpo do jornal, intitulada Cultura, sem um caderno específico. Semanalmente, o Público também publica suplementos como o Fugas, que aborda temas como gastronomia e viagens, e o $P 2$, focado em atualidades, o que inclui temas da área cultural.

\footnotetext{
4 Em uma alteração recente, o site do jornal Público adicionou a palavra "Cultura" como seção fixa na barra principal, que redireciona para a página do Ípsilon. O usuário ainda pode aceder a página ao clicar em ípsilon também em uma barra fixa.

5 No caso da Folha, o usuário tem de selecionar a palavra "Cultura" na página principal e será redirecionado para a página da Ilustrada.
} 
Cabe destacar, também, os dados referentes ao alcance dos jornais Público e Folha de S. Paulo, nas versões impressa e digital. De acordo com o site publicitário ${ }^{6}$ do diário, a edição impressa da Folha de São Paulo tem uma circulação de 328,1 mil exemplares, de segunda-feira a sábado, e 336,8 mil aos domingos. O tráfego mensal do seu site, com dados de janeiro de 2020, é de 238 milhões de page views e de 41 milhões de visitantes únicos ${ }^{7}$. Já os dados referentes à circulação impressa do jornal Público não foram localizados em seu site publicitário. Em relação à edição digital, o Público contabiliza 11,2 milhões de page views e 2,2 milhões de visitas ${ }^{8}$ em sua página principal. O material publicitário dos dois jornais afirma que a maior parte de seu público está nas classes A e B.

\subsection{A composição das amostras}

A composição das amostras dos dois jornais levou em conta a necessidade de coletar notícias do ano mais recente possível dentro do cronograma estabelecido para o projeto. Desse modo, o ano de 2018 foi escolhido para a coleta. Ainda que a questão dos arquivos digitais dos jornais tenha sido considerada desde 0 início, Folha e Público modificaram seus sites e seus arquivos no decorrer de nossa investigação. Desse modo, as peças da Folha puderam ser coletadas de seu arquivo, mas as do Público não.

\footnotetext{
6 Informações do Instituto Verificador de Circulação (IVC) dezembro de 2019. Acedido em abril de 2020, disponíivel em: www.publicidade.folha.com.br/folha

7 Informações do Google Analytics de janeiro de 2020. Acedido em abril de 2020, disponível em: http://www.publicidade.folha.com.br/folhadigital/

8 Informações da Netscope relativas a novembro de 2019. Acedido em abril de 2020, disponível em: https://comunique.publico.pt/publicidade/audiencia.html
} 
Foi utilizada, no caso do jornal português, a plataforma Factiva Database.

Outro aspecto relevante é o olhar cruzado entre os jornais, questão central para o projeto de investigação: buscamos peças sobre Portugal na cobertura cultural da Folha e sobre Brasil na cobertura de cultura do Público. Tendo em conta esse elemento, a solução encontrada para a composição da amostra foi o uso de palavras-chave para fazer a coleta. Foram utilizadas as seguintes palavras-chave para a busca das peças na seção digital de cultura do jornal Público: Brasil, brasileiro, brasileira, brasileiros e brasileiras. No caso da seção de cultura da Folha, utilizamos as palavras-chave a seguir: Portugal, português, portuguesa, portugueses, luso e lusa. Depois da coleta, foram eliminados os falsos positivos 9 .

Com esse processo, a amostra de peças do ano de 2018 é composta por 195 peças da Folha e 437 do Público. Ao todo, foram analisadas 632 peças em 15 variáveis diferentes. Apresentamos neste texto os resultados da variável Subsetor de Arte e Cultura, cujo objetivo era identificar os diferentes setores, áreas, produtos ou manifestações artísticas distribuídos na cobertura. $\mathrm{Na}$ grelha de análise havia 18 opções previstas e ainda a possibilidade de o analista adicionar uma opção, caso considerasse que as opções fornecidas não caracterizavam o setor predominante na peça.

9 Foram considerados falsos positivos as menções que não tinham nenhuma relação direta com os países e sua produção cultural, isto é, eram coincidências ou homônimos. Entre os falsos positivos, foram encontradas peças que entrevistavam pessoas que tinham como parte de seu nome as palavras Brasil ou Portugal. Há o caso do Hospital Beneficência Portuguesa, o da banda norte-americana Portugal. The Man e inúmeras referências ao idioma Português. 


\subsection{A Análise de Conteúdo}

Conforme Neuendorf (2002), a AC tem, entre suas características, a capacidade de sumariar, aspecto relevante em uma amostra de tamanho grande e diversa. Desse modo, Neuendorf (2002) salienta a necessidade de um desenho estrutural prévio, que inclua decisões sobre as variáveis, suas medidas e regras de codificação. Apesar das dificuldades inerentes à noção de objetividade, é necessário que haja consistência nas decisões e que se evite, ao máximo possível, enviesamentos e tendências. Em busca da confiabilidade como um elemento necessário à AC, Neuendorf (2002) sugere que sejam feitos pré-testes entre diferentes codificadores a fim de estimar o nível de concordância entre eles, tendo em conta, também, o número de sujeitos que irá codificar a amostra final.

Desse modo, foi realizado um pré-teste nas variáveis de acordo com a equação proposta por Lacy e Riffe (1996, p.965), com um intervalo de confiança de $5 \%$. O nível estimado de coincidência adotado foi de $80 \%$, que leva em conta a complexidade, o tamanho da grelha proposta e o requisito mínimo proposto por Lacy e Riffe (1996). Foi encontrado 90,4\% de coincidência entre os codificadores. Também foi elaborado um manual com instruções para a codificação de cada variável. 


\section{Um panorama dos Subsetores de Arte e Cultura nos jornais Folha de São Paulo e Público (2018)}

\subsection{Os subsetores na Folha de São Paulo}

Três subsetores predominam nas 195 peças analisadas do jornal Folha de São Paulo: Livros (32,3\% do total, 63 ocorrências), Música (21,5\%, 42 ocorrências) e Cinema (19\%, 37 ocorrências). Juntos, estão em $72,8 \%$ das peças publicadas em nossa amostra. Na sequência, estão Teatro com 9,2\% do total (18 ocorrências), Artes Visuais (5,6\%, 11 ocorrências) e Televisão (3,6\%, 7 ocorrências).

Entre os menos representados, há 11 subsetores com menos de 2\% do total cada. São eles: Arquitetura (1 ocorrência), Design (3), Economia da Cultura (1), Entretenimento (1), Festival Múltiplo (1), Fotografia (1), Gastronomia (3), Língua Portuguesa (3), Patrimônio Cultural (1), Política Cultural (1) e Séries (1). Juntos, esses 11 subsetores somam $8,7 \%$ do total.

Cabe destacar que caso o analista considerasse que as opções pré-estabelecidas não eram suficientes para caracterizar o subsetor predominante em determinada peça, ele tinha a opção de escrever na tabela o que considerava mais adequado. Entre os itens que foram adicionados pelo analista, a maioria aborda tópicos específicos que apareceram uma única vez, caso de Entretenimento e Festival Múltiplo, ou seja, com diferentes manifestações artísticas. Em contrapartida, há um que não estava 
previsto inicialmente na grelha e apareceu mais de uma vez: Língua Portuguesa (3 ocorrências). No caso da Folha de São Paulo, todas as peças analisadas tiveram um subsetor identificado.

\subsection{Os subsetores no Público}

Os setores que predominam na cobertura cultural do Público também são Música, Livros e Cinema que somados alcançam $60,2 \%$ das 437 peças analisadas. Com 33,2\% do total, Música está na primeira posição entre os subsetores observados - foram 145 peças. Foram registradas 62 ocorrências do subsetor Cinema (14,2\% do total) e 56 de Livros (12,8 \%). Na sequência, na quarta posição, está Artes Visuais com 12,1\% das peças (53 ocorrências).

Destacam-se, ainda que com percentagens inferiores, Língua Portuguesa (4,6\%, 20 ocorrências) e Patrimônio Cultural (3,43\%, 15 ocorrências). Como já mencionamos, Língua Portuguesa não estava previsto como subsetor na grelha de análise. Na sequência, estão os seguintes subsetores: Teatro (2,5\%, 11 ocorrências), Arquitetura (2\%, 9 ocorrências), Fotografia (2,3\%, 10 ocorrências), Televisão (2,3\%, 10 ocorrências) e Arquitetura (2\%, 9 ocorrências).

Os subsetores menos representados, com porcentagens inferiores a 2\% cada, são: Arte de rua (1 ocorrência), Cartoon (1), Dança (7), Design, (1), Festival Múltiplo (8), História (7), Jornalismo (2), Mais de uma subárea (2), Performance (5), Política (3), 
Política Cultural (4), Produção cultural (1) e Séries (3). Juntos, esses 13 subsetores somam 10,3\% do total de peças. Em uma peça única não foi possível identificar o subsetor principal, o que significa $0,23 \%$ do total.

\subsection{Convergências e divergências entre Folha de São Paulo e Público}

É importante iniciar com algumas considerações gerais a respeito da cobertura cultural dos dois jornais. As amostras têm tamanhos diferentes (195 peças da Folha e 437 do Público) porque a coleta foi feita, como já mencionamos, a partir de palavraschave. Desse modo, é possível dizer que, em 2018, há um número superior de peças do Público com palavras-chave relacionadas ao Brasil se comparado ao total de peças com palavras-chave relacionadas a Portugal na Folha. No entanto, a leitura do número total não permite saber quais peças realmente têm como foco central um artista, um produto ou uma manifestação artística de cada país, já que há muitas menções secundárias.

Nos dois jornais, há casos que não estavam previstos na greIha inicial, a maior parte com apenas uma ocorrência. Algumas vezes são denominações bem específicas, que configuram uma área ou especificidade. Um bom exemplo é Festival Múltiplo, ou seja, um festival que reunia diferentes subsetores e manifestações artísticas. Foram 8 ocorrências no Público e uma na Folha de São Paulo. 
Há casos de subsetores que aparecem apenas na cobertura de um dos dois jornais. Na Folha há registros de Economia da Cultura, Entretenimento e Gastronomia, enquanto no Público esses três estão ausentes. Já os subsetores que estão ausentes na FoIha mas presentes no Público são: Arte de rua, Cartoon, Dança, História, Jornalismo, Mais de um subsetor, Performance, Política e Produção Cultural. 0 Gráfico 1, abaixo, apresenta a distribuição dos subsetores nos dois jornais.

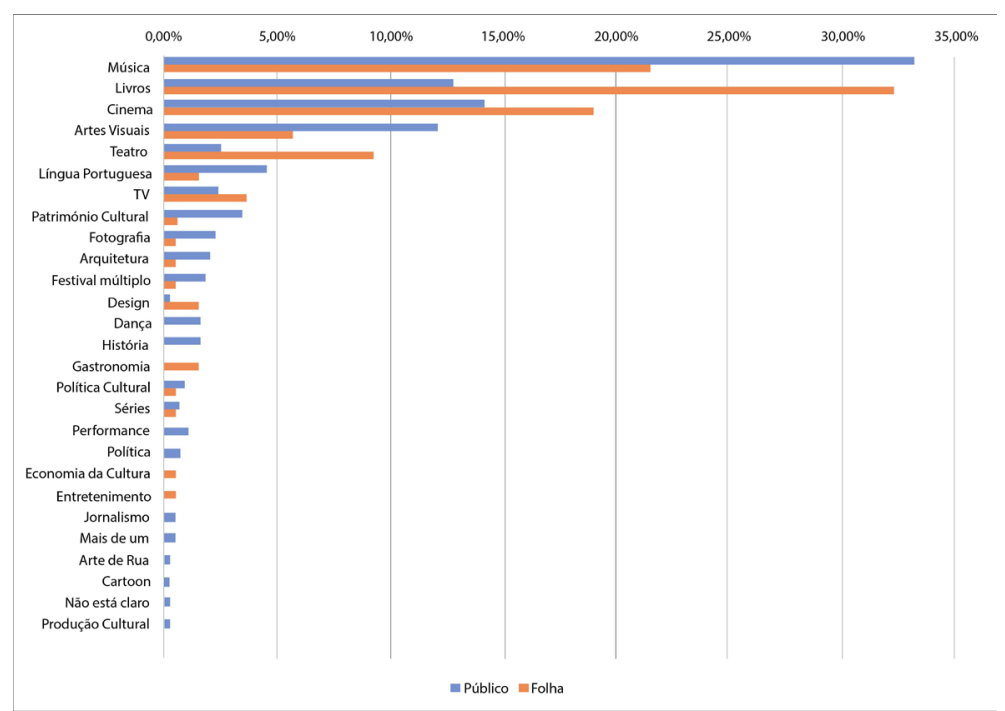

Gráfico 1: distribuição em percentagem dos subsetores nos dois jornais, Folha de São Paulo e Público

O predomínio de Música nas peças do Público (33,2\%), com palavras-chave sobre o Brasil, e de Livros (32,3\%) na Folha, com palavras-chave sobre Portugal, chama a atenção, visto que re- 
presentam, sozinhos, cerca de um terço do total de peças publicadas em cada jornal. Entre as divergências, destacamos o fato de a Folha de São Paulo cobrir mais Livros (32,3\%), Cinema (19\%), Teatro (9,2\%), Televisão (3,5\%) e Design $(1,5 \%)$ em comparação com o Público.

Por outro lado, o Público tem mais peças, em comparação com a Folha, nos seguintes subsetores: Música $(33,25 \%)$, Artes Visuais (12,3\%), Língua Portuguesa (4,6\%), Patrimônio Cultural (3,4\%), Fotografia (2,3\%), Arquitetura (2\%), Festival Múltiplo (1,8\%), Política Cultural $(0,9 \%)$ e Séries $(0,7 \%)$.

Entre as divergências, destacamos Artes Visuais, tema central de 12,3\% das peças do Público (53 ocorrências) e de apenas 5,6\% (11 ocorrências) na Folha. Ao ter em conta os títulos das peças, percebemos que três peças da Folha abordam o Museu de Arte de São Paulo (MASP) e duas o Instituto Inhotim, localizado em Minas Gerais. No caso do Público, destaca-se a presença da jornalista Isabel Salema, que assina individualmente a maior parte das peças sobre Artes Visuais do amostra, 21 de um total de 53.

Cabe mencionar, também, Língua Portuguesa, inserida manualmente nos dois jornais, com apenas 3 ocorrências na Folha e 20 no Público. Duas das peças da Folha são sobre o Museu de Língua Portuguesa, instituição localizada em São Paulo. Já no caso das peças do Público, há maior diversidade temática, mas uma concentração de formato e autoria: 15 das 20 peças sobre Língua Portuguesa são colunas de opinião assinadas por Nuno Pacheco. 
Ainda nas divergências, destacamos que 9,2\% (18 ocorrências) das peças da Folha abordaram Teatro, enquanto apenas 2,5\% (11 ocorrências) das peças do Público trataram sobre esse tema. Nas peças do Público, podemos identificar que duas abordam o Festival Internacional de Teatro de Expressão Ibérica (FITEI) e três a artista brasileira Christiane Jatahy, que foi Artista da Cidade de Lisboa em 2018. Não há uma repetição clara de temas na amostra da Folha, mas identificamos que 11 das 18 peças não têm a assinatura de nenhum jornalista ou agência de notícias. Das sete peças com assinatura, cinco são da mesma jornalista, Maria Luísa Barsanelli.

Cabe destacar, também, Design e Gastronomia, previstos na greIha inicial por inserirem-se na ideia de lifestyle, mas que tiveram poucas ocorrências nos dois jornais. No Público, foi identificada apenas uma peça sobre Design e, na Folha, foram três sobre Design e três sobre Gastronomia. No caso das peças sobre Design, da Folha, todas abordam, de alguma forma, a moda. Por outro lado, a única peça publicada no Público sobre Design foca em uma exposição sobre o tema, que ocorreu no Museu do Design e da Moda (Mude). Já no caso da Gastronomia, duas das três peças da Folha abordam a atividade de chefes de cozinha. É possível que essas temáticas sejam abordadas em outras seções dos jornais, ligadas ao turismo ou à beleza, por exemplo.

Em relação às ausências de subsetores previstos na grelha de análise, destacamos o fato de nenhuma peça da Folha, com palavras-chave sobre Portugal, abordar os subsetores Arte de Rua, 
Dança e Perfomance. No caso do Público, nenhuma peça, com palavras-chave sobre o Brasil, foca em Economia da Cultura e em Gastronomia.

Não é possível deixar de mencionar os subsetores que surgiram a partir da análise de cada peça, com o uso do recurso de preenchimento. Na Folha, foram inseridos os seguintes: Entretenimento, Festival Múltiplo e Língua Portuguesa. Há mais casos na cobertura do Público: Cartoon, Festival Múltiplo, História, Jornalismo, Língua Portuguesa, Mais de uma Subárea, Política e Produção Cultural. Apesar do caráter específico, esses subsetores indicam possíveis alterações na abrangência da cobertura cultural, inclusive porque alguns aparecem nos dois jornais, caso de Festival Múltiplo (com mais de uma subárea) e Língua Portuguesa.

\section{Considerações finais}

Este capítulo apresenta um panorama sobre os subsetores identificados na seção de cultura dos jornais Folha de São Paulo e Público em amostras estruturadas a partir de palavras-chave sobre Brasil e Portugal. Leva em consideração o fato de que a visibilidade é um elemento fundamental para agentes e produtos culturais e que o jornalismo cultural está entre os mediadores que atuam nesse processo (Janssen \& Verboord, 2015).

Enfatizamos, então, o fato de os dois jornais, em 2018, estarem centrados em grandes subsetores: Livros, Música e Cinema. Os 
três são segmentos de tamanho considerável e com grandes agentes, como editoras, gravadoras, produtoras e distribuidoras. No caso das peças do Público com palavras-chave sobre o Brasil, o que predomina é a Música (32,25\%). Já nas peças da Folha com palavras-chave sobre Portugal, o que predomina são os Livros (32,3\%).

Em relação aos setores pouco representados, há aqueles que podem indicar disputas ou questões conflituosas, caso de Economia da Cultura e Política Cultural, que aparecem pouco nos dois jornais. Já Gastronomia e Design, inseridas em uma concepção mais larga de produtos culturais, que inclui o lifestyle, também aparecem pouco na cobertura.

Os subsetores que foram inseridos manualmente pelo codificador, ainda que sejam específicos, podem indicar possíveis alterações nas temáticas da cobertura cultural. Dois deles, Festival Múltiplo e Língua Portuguesa, aparecem na análise dos dois jornais, por exemplo. As ocorrências que abordam mais de um subsetor, caso de Festival Múltiplo (8 ocorrências no Público e uma na Folha) e Mais de um setor (2 ocorrências no Público) são interessantes porque Kristensen (2010) já apontava uma tendência ao hibridismo na cobertura cultural, com peças que contemplam mais de um setor. Faz sentido, portanto, acompanhar esses casos pontuais, visto que podem vir a constituir uma mudança na abrangência da cobertura jornalística da cultura.

Por fim, cabe dizer que uma compreensão mais ampla a respeito dos Subsetores de Arte e Cultura pressupõe um cruzamento 
sistemático com outras variáveis como autoria, formato jornalístico, valores-notícia e fontes.

\section{Bibliografia}

Alsina, M. R. (2009). A construção da notícia (1. ed.). Petrópolis: Vozes.

Baptista, C. (2017). Jornalismo cultural em Portugal - retrato de uma década e projecções para o futuro. In Baptista, C. (Ed.), A Cultura Na Primeira Página - Uma década de jornalismo cultural na imprensa em Portugal (pp-43-85). Lisboa: Escritório Editora.

Berger, P., \& Luckmann, T. (2010). A construção social da realidade: tratado de sociologia do conhecimento (32a ed.). Petrópolis: Vozes.

Berger, C. (2003). Campos em confronto: a terra e o texto (2.ed.). Porto Alegre: Editora da UFRGS.

Bourdieu, P. (2004). Coisas ditas. São Paulo: Brasiliense.

Bourdieu, P. (2005). A economia das trocas simbólicas. São Paulo: Perspectiva.

Bourdieu, P. (2008). A produção da crença: contribuição para uma economia dos bens simbólicos. 3aed. Porto Alegre: Zouk.

Bourdieu, P. (2010). O Poder Simbólico. 14ąed. Rio de Janeiro: Bertrand Brasil.

Bourdieu, P. (2011). A distinção: crítica social do julgamento. 2aed. Porto Alegre: zouk.

Hall, S., Chritcher, C., Jefferson, T., Clarke, J., \& Roberts, B. (1999). A produção social das notícias: o mugging nos media. In N. Traquina (Ed.), Jornalismo: questões, teorias e "estórias", 2.ed.. Lisboa: Vega, pp. 224-262.

Janssen S. (1999). Art journalism and cultural change: The coverage of the arts in Dutch newspapers 1965-1990. Poetics, 26, pp. 329-348, disponível em: https://doi.org/10.1016/S0304-422X(99)00012-1. 
Janssen, S., Verboord, M., (2015). Cultural Mediators and Gatekeepers. In James D. Wright (ed.), International Encyclopedia of the Social \& Behavioral Sciences, 2nd edition, Vol 5, pp. 440-446. Oxford: Elsevier.

Kristensen, N. N. (2010). Cultural journalism in the Danish printed press - a history of decline or increasing media institutional profiling?. Nordic Journal of Media Studies, 8, pp. 69-92, available in: https://doi. org/10.1386/nl.8.69_1.

Lacy, S. \& Riffe, D. (1996). Sampling Error and Selecting Intercoder Reliability Samples for Nominal Content Categories. Journalism \& Mass Communication Quarterly, 73(4), pp. 963-973, available in: https:// doi.org/10.1177/107769909607300414.

Neuendorf, K. A. (2002). The content analysis guidebook. Thousand Oaks: Sage.

Miguel, L. F. (1999). O Jornalismo Como Sistema Perito. Tempo Social, 11(1), pp. 197-208, available in: https://doi.org/10.1590/S010320701999000100011.

Santos Silva, D. (2016). Cultural Journalism in a Digital Environment-New Models, Practices and Possibilities. Tese de Doutoramento, Faculdade de Ciências Sociais e Humanas da Universidade Nova de Lisboa, Lisboa, Portugal, available in: http://hdl.handle.net/10362/17022. 